\title{
THE INSTITUTION FOR INVESTIGATING THE NATURE AND CURE OF CANCER. A STUDY OF FOUR EXCERPTS*
}

\author{
by
}

VICTOR A. TRIOLO

\begin{abstract}
In fact, little is at present known of cancer, but as an incurable disease; and after a great number of trials and attempts to discover a method of cure, the faculty seems to have been reduced to a state of despondency; as if both science and art were exhausted, or were unequal to the difficulties they have to encounter.
\end{abstract}

Thomas Denman, M.D., 1802

DURING the last quarter of the eighteenth century, English medical practice began to derive the benefits of scientific inquiry instituted at the leading clinics of the kingdom. ${ }^{1}$ This era witnessed the emergence of vigorous schools in pathology and dermatology, which, among other celebrated signs, took shape from such works as Matthew Baillie's Morbid Anatomy and Robert Willan's Cutaneous Diseases. The elements of Baillie's treatise, published in $1793,{ }^{2}$ were performed in scope and content in the anatomical collections of his eminent uncle, John Hunter, whose museum illustrated a 'multitude of pathological facts'. ${ }^{8}$ The various parts of the treatise, nevertheless, show innovations incorporated from Baillie's personal experiences as physician to St. George's Hospital, an office he held jointly with a lectureship in anatomy at the Great Windmill Street School.4 Willan's monograph first appeared in $1808 ;^{5}$ however, it represents the labours of more than twenty years, in the course of which he accumulated observations from several medical appointments, particularly through his post as chief physician to the Carey Street Dispensary. ${ }^{6}$

The overt enthusiasm for scientific studies within the hospitals and dispensaries is equally reflected in the strengthening of professional communications through such alliances as the 'Society for the Improvement of Medical and Chirurgical Knowledge' (1784). Much of the stimulus towards the establishment of these associations ${ }^{7}$ came from John and William Hunter, to whom British medical men applied in large numbers for guidance in the study of anatomy ${ }^{8}$ and pathological anatomy. Moreover, the enlargement of hospital facilities in the eighteenth century ${ }^{9}$ afforded greater opportunities for clinical investigations on a multitude of diseases including cancer, a subject largely obscured by traditional errors and imperfections. ${ }^{10}$ British medical men were now aroused to the inescapable requirements for additional knowledge in this as in other departments of pathology.

As the only hopeful measure in the treatment of cancer was prompt recourse to surgery, this field entered the foreground of the renewal of interest in oncology late

*This study was supported, in part, by a Research Career Development Award (5K03 CA 17850 HM) from the National Cancer Institute, United States Public Health Service. Partial support also was received from the Fels Research Institute of Temple University School of Medicine. 


\section{Victor A. Triolo}

in the eighteenth century. At this time a monumental discovery was made by Percival Pott (1713-1788), surgeon to St. Bartholomew's Hospital. Pott described the peculiar liability of chimney sweeps to cancer of the scrotum and he traced the causes of the disease to the lodgement of soot and the irritation incurred thereby by the scrotal tissues. However, his report of this disorder, in $1775,{ }^{11}$ did not specify the most efficacious means for its repair; prompt excision of the affected parts and removal of the injurious influences occasioned by this occupation. John Hunter (1728-1793) also advanced the operative treatment of tumours, which he predicated upon a novel interpretation $^{12}$ of the nature and causes of cancer. Many of Hunter's successors espoused his progressive views, ${ }^{13}$ and a number of them entered a collaborative endeavour, an 'Institution for the Investigation and Cure of Cancer', established within the decade following his death. The Cancer Institution became a conjoint endeavour of the physicians and surgeons of London, a compact that flourished under the protection of their respective Colleges.

This essay will attempt to lift this question into a more revealing light by examining four separate accounts of the Cancer Institution, each reproduced below.

\section{EXCERPTS}

1. THE EDINBURGH MEDICAL AND SURGICAL JOURNAL ACCOUNT ${ }^{14,15,16}$

The Medical Committee of the Society for Investigating the Nature and Cure of Cancer, consisting of Drs. Baillie, Sims, and Willan: Mess. Sharpe, Home, Pearson, and Abernethy, and Dr. Denman, Secretary, circulated in 1802 a set of Queries for obtaining information regarding these. Since that time they have been republished, with Observations explanatory of their object. In reprinting a Brochure of so much intrinsic value, we hope both to preserve it, and to forward the views of so laudable an institution.

Every person must be sensible of the various difficulties attending the establishment of a new institution, and of the much greater and more numerous difficulties which beset our first steps in the acquisition of knowledge on a subject of which, it may be said, we are even at this time totally ignorant.* But, in order to form a basis of inquiry, in which the nature and cure of cancer, it is presumed, may be pursued with all the advantages of reason and experience, the Medical Committee very early drew out and distributed the following queries, for the consideration not only of the corresponding members, but of all medical men, to whom opportunities of answering them might, by study or accident, occur. A satisfactory answer to any one of these queries would, in itself, be of great importance, and might probably lead to an explanation of others. It is therefore earnestly requested, if any new observation or discovery respecting cancer should be made, that it may be communicated to the secretary of this institution; and, if any progress in the investigation of the nature and cure of cancer be made or imparted to them, it will, without delay, be laid before the public by the Medical Committee. It may be necessary to observe that the promoters of this institution have never entertained the idea of creating the jealousy, or of interfering with the interests, of those who are engaged in institutions of a similar kind; their intention being solely that of co-operating in the laudable endeavour to lessen the mass of human misery, by calling for the assistance of others, and by exerting themselves to obtain a remedy for a most painful and dreadful disease, against which all medicines and methods of treatment hitherto proposed and tried have been unavailing.

The queries above-mentioned are expressed in as plain terms as the nature of the

*It is scarcely necessary, in this place, to refer the reader to an excellent Treatise on Cancer, by Mr. Pearson, surgeon of the Lock Hospital. 


\section{Institution for Investigating the Nature and Cure of Cancer}

subject would allow; but it has been thought that some benefit would accrue from a short comment or explanation of the aim and purpose of each query in the following manner:...

\section{THE BERNARD ACCOUNT ${ }^{17,18,19}$}

No. XCIX. Extract from an Account of the Institution, for investigating the nature and cure of Cancer, By Thomas Bernard, Esq.

In June 1801, there was formed in London an institution for investigating the nature and cure of cancer; a disease to which the rich, as well as the poor, are liable; but which seems to bear more hardly on the latter, as wanting that alleviation of pain, and that degree of attention and assistance, which an evil so hopeless, and so aggrevated, must require. Dr. Denman, whose medical practice has placed him very much in the way of knowing and seeing the dreadful consequences of this disease among the female sex, had the merit of proposing a meeting on the subject of this charity. A Committee of superintendence, consisting of 21 gentlemen, has been appointed together with a medical committee, to direct the medical affairs of the institution. This committee consists at present of 14 professional men of the first eminence.* Each committee possesses the power of electing their own members, and of increasing the number to a limited extent. Dr. Denman is the secretary of the medical committee, and the person to whom all communications, on the subject of the institution, are to be sent. There are already upwards of 50 corresponding members** in different parts of the world: and the object of this society being to draw into one focus every information, as to symptom or remedy, which can be obtained, the number of corresponding members will of course be unlimited; and a place in the list will be open to any professional man (in any part of the world) who is recommended by any member of the medical committee.

The subscriptions, including a donation from some of the life governors of the Infant Asylum, amount at present to about $£ 300$; which has already been invested in the purchase of stock. The donation of $\mathbf{3 0}$ guineas constitutes a governor for life. Any benefaction,*** however, is received with acknowledgment; and without

*The members of this committee are Dr. Gisborne (President of the College of Physicians), Mr. Long (Master of the College of surgeons), Sir George Baker, Bart., Dr. Baillie, Dr. Heberden, Dr. Hunter, Dr. Sims, Dr. Willan, Mr. Abernethy, Mr. Blizard, Mr. Cline, Mr. Home, Mr. Pearson, and Mr. Sharp.

**The following queries have been prepared under the direction of the medical committee, and ordered to be sent round to the corresponding members:

1. What are the diagnostic signs of cancer?

2. Does any alteration take place in the structure of a part, preceding that more obvious change which is called cancer? If there does, what is the nature of that alteration?

3. Is cancer always an original and primary disease, or may other diseases degenerate into cancer?

4. Are there any proofs of cancer being an hereditary disease?

5. Are there any proofs of cancer being a contagious disease?

6. Is there any well-marked relation between cancer and other diseases? If there be, what are those diseases to which it bears the nearest resemblance, in its origin, progress, and termination?

7. May cancer be regarded at any period, or under any circumstances, merely as a local disease? or, does the existence of cancer in one part, afford a presumption, that there is a tendency to a similar morbid alteration, in other parts of the animal system?

8. Has climate, or local situation, any influence in rendering the human constitution more or less liable to cancer, under any form, or in any part?

9. Is there a particular temperament of body more liable to be affected with cancer than others? and if there be, what is that temperament?

10. Are brute-creatures subject to any disease, resembling cancer in the human subject?

11. Is there any period of life absolutely exempt from the attack of this disease?

12. Are the lymphatic glands ever affected primarily in cancer?

13. Is cancer under any circumstances susceptible of a natural cure?

***Benefactions are received by the Treasurers, Stephen Aisley, Esq. and Thomas Phillip Hampson, Esq. by the Secretary, and by the following bankers; Down, Thornton, and Co.-Glynn and Co.Hoares,-Drummonds,-Ransom, Morland, and Co.-Dorset, Wilkinson, Berners, and Co.and Devaynes, Dawes, Noble, and Co. 


\section{Victor A. Triolo}

expectation of its being repeated, unless the donor shall, at any time, think fit. To the attendance of patients at their own houses, it is to be hoped the charity will soon be competent, and a regular register of cases, and of the effects of the remedies applied, will then be commenced. But as it is known that in poor families, when one of the members is afflicted by cancer, it is absolutely impossible that they should be supplied with the means even of decent and tolerable cleanliness, it is in contemplation that, as soon as the funds of the charity will authorize it, a house shall be hired for the sole reception of cancerous patients; to be admitted for a certain period without any expense, and afterwards, in peculiar cases, to be continued at a limited and moderate charge; so as to relieve the poor from a burthen, not merely exceeding their means of expenditure, but requiring a constancy of attention, incompatible with their call to business, or daily labour, for their support.

When such a house shall be established, it is intended that there shall be a resident apothecary, competent by his integrity, his intelligence, and his industry, to make the experiment of any mode of cure, which it may be thought proper to adopt: and that a physician and surgeon shall be elected, (not for life, but for three, five, or seven years) to whom some acknowledgment shall be made, for extraordinary attention to the objects of the institution. No experiments are, however, to be made, nor any new medicine tried, except by the express authority of the medical committee.

\section{OBSERVATIONS}

In the long train of diseases to which human nature is subject, no one is attended with more hopeless misery than that which is denominated cancer, whatever part of the body may be the seat of it.**** This occurs far more frequently than is generally supposed; and a calamity so pitiable as that of persons afflicted with cancer, in any rank or situation in life (all being alike subject to them) it is hardly possible to imagine; their suffering being aggravated by the present insufficiency of medicine, to afford any proportionate relief. For, setting aside the benefits that are obtained by the use of these means, which give a short respite to the anguish which such patients endure, there is no physician, nor any medical man of reputation, who would hesitate to admit that his knowledge of any method, by which this disease may be prevented, or even its progress retarded, is very defective; and that, when it is confirmed, he does not entertain even a hope of curing it. In fact, little is at present known of cancer, but as an incurable disease; and after a great number of trials and attempts to discover a method of cure, the faculty seems to have been reduced to a state of despondency; as if both science and art were exhausted, or were unequal to the difficulties they have to encounter.

It has, however, pleased God that means should be discovered for the cure of diseases, which once thought incurable. We ought, therefore, to hope that a remedy may at length be found out for cancer; and, with such hope, it is the duty of medical men to exert their faculties, for the investigation of the nature and cause of them, and for the discovery not only of the means of relief, but of cure. The experiments which have been hitherto made, seem not only to have been imperfectly conducted, but their results have been ill recorded. In the present enlightened state of medicine, both these things would certainly be rectified, and new experiments might be suggested, to obtain this most desirable end. But the duties of general practice perpetually interrupt the attention of those who have capacity, and inclination, to pursue this object, with the energy it requires. The institution, for the reception of patients afflicted with cancer, is therefore formed, not merely with a design of affording an asylum for the distressed, but professedly for the purpose of experiment and discovery. It may also be reasonably presumed that, in this research for the cure of cancer, more accurate knowledge, and more efficacious methods, of curing some

****These observations, and part of this account, are extracted from Dr. Denman's address to the public on this interesting subject. 


\section{Institution for Investigating the Nature and Cure of Cancer}

other diseases will be discovered. Nor ought it to be passed in silence, that every medical man to whom this institution has been mentioned, has expressed his approbation of it, and his determination to support its establishment.

28 th May, 1802.

\section{THE DENMAN ACCOUNT ${ }^{20}$}

I shall conclude what remains to be said on this subject [cancer], with a short account of a charity instituted in London, in the year 1801, for the purpose of investigating the nature and cure of Cancer.

Several conversations had passed between different professional gentlemen on the cause, nature, and cure of Cancer. As trials of medicines cannot probably be conducted with such accuracy in private practice as in public institutions, it was at length proposed that measures should be taken for the establishment of a Charity, or institution, for the express purpose of investigating the nature of Cancer, and of making experiments, for the discovery of a method of curing that disease. Applications were immediately made to many gentlemen to support such an institution, and the subscriptions were beyond all expectations liberal. In a short time it was thought justifiable and proper, to form the establishment, which was accordingly done without delay.

At a very respectable meeting of the Subscribers, Mr. John Pearson, of Golden Square, was nominated Surgeon of the Institution, with an understanding, that it should be chiefly under his care and direction; for though this gentleman had not written particularly on the subject, such was the general opinion of his abilities and integrity, from his writings and character, that there was not, nor could be, the least objection made to his being appointed.

To Mr. Pearson I am obliged for several of the preceding remarks.

Treasurers and other officers were chosen, and a house was taken for the purpose, in Henry Street, Tottenham Court Road; the situation being healthy, and not too far distant, it was thought, for medical attendance.

After some time Dr. Pelham Warren, Dr. John Willan, and Dr. Thomas Young, were elected Physicians; and the principal Physicians and Surgeons in this city were invited to give their assistance, and to suggest any means by which the ends of the Institution were likely to be answered most effectually.

In conformity to the general design of the Institution, there were kept regular histories of the cases, of the medicines administered, and of the final issue of the cases. Where favourable opportunities offered, cancerous parts were carefully dissected, some preparations made, and a few drawings of extraordinary appearances taken.

Notwithstanding these exertions, it appeared that the great primary objects of the Institution were imperfectly answered, owing to various causes, which it is not necessary to repeat.

For the purpose of rendering the Institution more adequate to the original intention, at a meeting of the Subscribers it was determined:

1. That the Constitution of the present Charity shall be dissolved;

2. That the house intended for the reception of patients, ought to be in a more populous and convenient part of town;

3. That means for admitting a greater number of patients into the house should be taken into consideration.

The Institution was accordingly suspended for the present, and when the accounts were settled, there was left a considerable sum of money, which now amounts to near one thousand pounds, three per Cent. Consols, in the hands of the Drummonds, and standing in the name of five trustees. It is to be hoped that at some, not very distant time, the sum so remaining may, by the additional subscription of the former Governors, or by the general beneficence of the public, be applied to the support 


\section{Victor A. Triolo}

of a new Establishment for the same laudable purpose, and free from the inconveniences of the former Institution.

The Cancer Institution was carried on with much spirit for about two years, during which time forty-one patients applied for relief; eleven were admitted into the house, and thirty have been relieved as out-patients: all the in-patients, which were regularly attended, received as much benefit as the nature of their cases allowed. Two were relieved by the extirpation of the disease.

Of the out-patients twenty-eight had advice and medicines. In addition to the cases for which the Institution was originally established, thirteen patients afflicted with other diseases resembling Cancer, and which are mistaken for it, have been cured. One in-patient and four out-patients have died.

London, 1 November 1810.

\section{THE HIGHMORE ACCOUNT ${ }^{21,22}$}

Institution for investigating the Nature and Cure of Cancer.

In the month of June, 1803, a charitable society was formed in London for the above important purpose. The cancer bears more hardly on the poor than on the rich, as wanting that alleviation of pain, and that degree of attention and assistance, which an evil so hopeless and so aggravating require. Dr. Denman, whose medical practice has placed him very much in the way of knowing and seeing the dreadful consequences of this disease among the female sex, had the merits of proposing a meeting on the subject, and became a most active member of this charity. A committee of superintendence, consisting of twenty-one gentlemen, was appointed, together with a medical committee to direct its affairs. The medical committee consisted of fourteen practitioners in medicine and surgery of the first eminence. Each committee had the power of electing its own members, and of encreasing the number to a limited extent. Dr. Denman was the secretary of the medical committee, and the person to whom all communications on the subject were and may still be addressed. There were above fifty corresponding members in different parts of the world: and the object of the society being to draw into one focus every information as to symptom or remedy which could be obtained, the number of correspondents was of course unlimited.

The subscriptions, including a donation from the infant asylum, had been invested in the funds. A donation of thirty guineas constituted a governor for life. Any benefaction was accepted, without expectation of its being repeated, unless the donor should at any time think fit. But as it was known that in poor families, where one of its members is afflicted by cancer, it is absolutely impossible that they should be supplied with the means even of decent and tolerable cleanliness, it was in contemplation that as soon as the funds of the charity would authorize it, a house should be hired for the sole reception of cancerous patients; to be admitted for a certain period without any expense, and afterwards, in peculiar cases, to be continued at a limited and moderate charge; so as to relieve the poor from a burthen, not merely exceeding their means and expenditure, but requiring a constancy of attention incompatible with their call to business or daily labour for their support. In this establishment a resident apothecary was necessary; competent by his integrity, intelligence, and industry, to make the experiment of any mode of cure which it might be thought proper to adopt: and a physician and surgeon elected for three, five, or seven years, to whom an acknowledgment should be made for extraordinary attention to the objects of the institution. No experiments were to be made, nor any medicine tried without the express authority of the medical committee.

Dr. Denman in his able and humane address to the public on the opening of this society, states it as a fact, that 'little is at present known of cancer but as an incurable disease, as if science and art were exhausted, or were unequal to the differences they have to encounter, and that the institution was formed not merely with a design 


\section{Institution for Investigating the Nature and Cure of Cancer}

of affording an asylum for the distressed, but professedly for the purpose of experiment and discovery.*

The officers chosen were Stephen Aisley, esq. and Thomas Philip Hampton, esq. treasurers; the medical department was to be conducted by Dr. Willan, Dr. Pelham Warren, Dr. Denman, and Dr. Young, physicians; and by Mr. J. Pearson, surgeon. A house was taken for this benevolent purpose, and numerous subscriptions were received, but after a short time it was judged expedient by the managers to close the accounts of the institution at Christmas, 1805; its finances were not wholly exhausted in the experiment, and the remnant was invested in the funds in the names of trustees to await a more favourable opportunity for renewing the progress of the charity; it is however to be remembered that in several of the established hospitals, wards have been wholly appropriated, and part of their medical practice devoted, to the cure or relief of cancer.

${ }^{*}$ Rep. Soc. B. C. Poor, iii, 259.

Discussions on the question of a Cancer Institution probably were initiated by medical men under the aegis of Thomas Denman (1733-1815), as the second and fourth excerpts suggest. Denman's ample experiences with the disease were summoned from a multi-faceted career. ${ }^{23,24,25,26}$

Several excerpts refer to another medical founder of the cancer charity, the surgeon John Pearson (1758-1826), ${ }^{27}$ who served his apprenticeship under William Hey at the Leeds General Infirmary. Pearson is described as a 'careful surgeon, with a strong scientific bias'. ${ }^{28} \mathrm{He}$ was not a prolific author, although his publications encompass a wide assortment of medical and scientific matters. Included among them is a small collection of clinical observations on cancer, issued in $1793,{ }^{29}$ a work apparently unknown to Denman, who in his own account remarks that Pearson had 'not written particularly on the subject'. Nevertheless, Pearson's eminent rank in clinical affairs at the turn of the nineteenth century, together with his well-laid claim to a knowledge of cancer, fitted him in the estimation of his colleagues ${ }^{30}$ for the surgeoncy at the Cancer Institution.

The Cancer Institution perhaps would never had materialized had it not been favoured by a company of philanthropists, the 'Society for Bettering the Condition and Increasing the Comforts of the Poor', founded in 1796 for the purposes of eliminating pauperism and improving the lot of the labouring classes. This charitable league, inaugurated by Sir Thomas Bernard (1756-1817), ${ }^{31}$ endeavoured to correct the social inequities spawned by the unbridled spread of industrialism and mercantilism. Bernard, scion of a noble and well-placed family, obtained a distinguished following, including William Wilberforce and Benjamin Thompson (Count Rumford), in his mission of promoting benevolent works throughout England. The Poor Society was chiefly responsible for encouraging popular appreciation and exploitation of the mechanical arts through its establishment of the Royal Institution, under Count Rumford, in 1799.

An endowment from the Poor Society was made available for the Cancer Institution under the following circumstances:

In June, 1799, the Committee of the Society for Bettering the Condition of the Poor had established an Infant Asylum, which has two objects; the preservation of a peculiar class of infants, and the supply of wet nurses for the children of some of the other classes. The irreconcilable enmity and jealousy however of the nurses and female attendants soon broke up the new establishment; and on its ruins was erected in June, 1801, the Cancer Institution. Dr. Denman, whose medical practice had given him many opportunities of knowing and observing the dreadful consequences of this disease, had the merit of proposing a meeting on this subject, and became 


\section{Victor A. Triolo}

a most active member of the charity. The first object was to collect every information as to the symptoms or remedy, which could be obtained from corresponding members in different parts of the world; and afterwards hire a house for the reception of patients labouring under this disease. $^{\text {22 }}$

The affairs of the Cancer Institution remained under the close surveillance of the Poor Society, ${ }^{33}$ whose principal patron doubtless assumed a primary role in shaping the foundations of the cancer charity. ${ }^{34}$

The Medical Committee of the Cancer Institution was composed of men of the highest stature in their respective professions, including Sir Thomas Gisborne (d. $c$. 1806), ${ }^{35}$ President of the Royal College of Physicians; Sir George Baker (1722-1809) ${ }^{36}$ a long-time President of the College of Physicians; William Heberden the Younger (1767-1845);37 and Robert Willan (1757-1812). The epidemiological experiences of Heberden and Willan are emphasized in several of the Queries devised by the Medical Committee.*

Prior notice has been taken of the broad professional activities of Thomas Denman and Mathew Baillie (1761-1823), both of whom were joined on the Medical Committee by a colleague, James Sims (1741-1820). ${ }^{38}$

The surgeons were represented by the presiding officer of their craft, William Long (c. 1749-1818), ${ }^{39}$ Sir William Blizard (1743-1835), ${ }^{40}$ and Sir Everard Home (1756-1832). ${ }^{41}$ The latter was an avowed student of cancer, and wrote two works on the subject, ${ }^{42}$ although he displayed no superior talents as a creative investigator.

Also included was John Abernethy (1764-1831), ${ }^{\mathbf{4 3 4 4}}$ whose numerous additions to the advancement of medical knowledge include some illuminating observations on tumours; ${ }^{45}$ and Henry Cline (1750-1827), ${ }^{46,47,48}$ who came to the Medical Committee as the representative of St. Thomas's Hospital.

One other surgeon, beyond John Pearson, is cited in several excerpts, namely Mr. Sharp, whose identity remains undisclosed. ${ }^{49}$

The cancer society formulated two objectives. First, full particulars on cancer were to be obtained from colleagues at home and abroad. This purpose was answered by the Queries, though no record of a Committee of Correspondents is preserved. Owing to the war then in progress with France, and despite the brief peace of Amiens concluded in March 1802, it is doubtful that any but the most perfunctory communications were established with foreign workers. On the other hand, the Queries probably were well known within British medical circles. The Medical Committee, in the second place, was to devise a programme of medical assistance for victims of cancer. This purpose was answered by a charity, presumably fitted up late in 1803 in a house near Tottenham Court Road. ${ }^{50}$

This latter development may be examined with somewhat greater facility by means of an analogy made with respect to another endeavour of contemporary interest. We refer to the 'Institution for the Cure and Prevention of Contagious Fever', ${ }^{51}$ which remains a monument to the memory of Robert Willan. In 1800 and 1801 the typhus raged in London. Willan, in his reports, pointed to the great misery occasioned by these inundations of contagion and he recommended the erection of 'Houses of Recovery' such as were provided at Manchester, Chester and Waterford.

But where is a remedy to be found for so many evils? Hospitals are either barred against the entrance of contagious diseases, or if leave of entrance be obtained, it generally comes when the patient is incapable of being removed, there being but one day throughout the week in which he can be admitted, unless by some particular interest. Pecuniary aid, whether transmitted by the warm heart of benevolence, or wrenched from the slow, reluctant hand of parochial administrators, is an insufficient palliative for the present case. Shall the unhappy patient then

*Note the fifth and eighth Queries. However, special studies on the epidemiology of cancer are not evident at this time. See Howard, Plan for the Relief of Cancer, p. 33. 


\section{Institution for Investigating the Nature and Cure of Cancer}

seek for refuge in the parish workhouse? Alas! the Fever is already making its ravages there. What therefore is to be done? All these mischiefs admit of ready alleviation, and might with proper management, be removed at a moderate expense. Let Houses of Recovery be established in open, airy situations, at some distance from other buildings, but adjoining to different districts of the metropolis; to be supported either at the joint expense of the several parishes within each district, or by a voluntary subscription among its principal inhabitants. As soon as any person exhibits symptoms of a Fever from infection, let him be instantly removed into the House of Recovery, where, being washed, and put, with clean linen, into a fresh bed, he will soon be freed from his complaints, and be able to rejoin his wife and family. ${ }^{62}$

Willan referred his petition to the Poor Society, a delegation of which, on 9 April 1801 , endorsed his design for a 'House of Recovery' at a location on Gray's Inn Road. The inhabitants of this district forced opposition to the project, but without success, and the plan was executed at the opening of the Fever Institution, on 9 February 1802, under Willan as 'physician extraordinary'. A crisis ensued when a protégée of Willan, Dr. T. A. Murray, 'was unfortunately cut off in February 1802, by the contagion of fever caught in the infected apartments of the first patients who were admitted into the institution'. ${ }^{53}$ The enterprise prospered, however, by virtue of the visible improvements in the health of the inmates and the abatement of the epidemic following the sanitation of their former residences. The Fever Institution was so well established by 1804 that it received a parliamentary award of $£ 4,000$.

Responsible medical opinion of this period largely favoured the hypothesis that cancer was transmitted through some infective entity, ${ }^{54}$ a view no doubt shared by various members of the Medical Committee. ${ }^{55}$ This issue could not have been removed from deliberations on the resolution subsequently adopted for the medical relief of those afflicted with cancer. With full knowledge of the impediments imposed upon a policy of providing house service for cancer patients, usually abandoned to an existence of utter desolation, the Medical Committee judiciously discarded this impractical formula. The architects of the Cancer Institution, perhaps mindful of the auspicious outcome of the Fever Institution, instead projected a similar refuge in a sequestered quarter of the city. The valued experiences of Willan were invoked once again, and his election as chief physician of the cancer charity was concluded at the time of his resignation, in December 1803, from the Carey Street Dispensary.

Two physicians, not yet eligible for the full preferments of their profession, were invited to participate in this undertaking. They were Pelham Warren (1778-1835), ${ }^{56}$ and Thomas Young (1773-1829). ${ }^{57,58}$

We have previously noted the instalment of John Pearson as surgeon to the Cancer Institution. This commission evidently offered no obstacle to his performances at the Carey Street Dispensary, with which he remained affiliated until 1809, and at the Lock Hospital, from which he resigned in $1818 .{ }^{59}$

Nothing further is given beyond a cursory remark in the Bernard account concerning an apothecary, "competent by his integrity, his intelligence, and his industry, to make the experiment of any mode of cure'. The physicians and surgeons, not inconceivably, would have viewed with some discomfort the presence of this profession in their midst, nor would the service of an apothecary be deemed indispensable. ${ }^{60}$ Table I (p. 20) presents in summary the various affiliates of the Cancer Institution.

The Cancer Institution was intended not only as an 'asylum for the distressed', but also for the objects of 'experiment and discovery' (Bernard account, Obs.), such designs having been effected 'where favourable opportunities offered' (Denman account). Matthew Baillie ceased his investigations on pathological anatomy after $1800,{ }^{61}$ yet his earlier inquiries afforded a sound basis ${ }^{62}$ for an enlargement of knowledge on the structure of tumour formations. Everard Home was drawn to the study of cancer, with particular regard to its clinical manifestations, through the exhortations of Denman. ${ }^{63}$ Home, nevertheless, became a vigorous proponent of cancer research, ${ }^{64}$ and he met criticisms of this work with forthright reproach, 'This is productive of 


\section{Victor A. Triolo}

two evils; the obscure diseases remain uninvestigated, no approach being made towards discovering remedies for them; and the patients become a prey to mercenary empirics.' ${ }^{\text {65 }}$

\section{TABLE 1}

The Institution for Investigating the Nature and Cure of Cancer ${ }^{1}$

\section{A. COMMITTEE OF SUPERINTENDENCE \\ Treasurers \\ Stephen Aisley, Esq. \\ Thomas Philip Hampson, Esq.}

B. MEDICAL COMMITTEE

Physicians

Dr. Thomas Gisborne, President of the Royal College of Physicians

Sir George Baker, Bart.

Dr. Thomas Denman, Secretary of the Institution

Dr. Matthew Baillie

Dr. William Heberden, Jun.

Dr. James Sims

Dr. Robert Willan

Dr. Hunter ${ }^{2}$

\section{Surgeons}

Mr. William Long, Master of the Royal College of Surgeons

Sir William Blizard

Sir Everard Home

Mr. John Abernethy

Mr. Henry Cline

Mr. John Pearson

Mr. Sharp ${ }^{3}$

C. STAFF OF THE CANCER INSTITUTION

Physicians

Dr. Robert Willan, Chief Physician

Dr. Thomas Young

Dr. Pelham Warren

Surgeon

Mr. John Pearson, Chief Surgeon

Apothecary ${ }^{3}$

D. CORRESPONDENTS ${ }^{3}$

1 The Committee of Superintendence and the Medical Committee comprise the Society for Investigating the Nature and Cure of Cancer.

2 Cited only in the Bernard Account, probably erroneously.

Unidentified or unknown. 


\section{Institution for Investigating the Nature and Cure of Cancer}

A novel interpretation relating to tumour systematics was brought forth by John Abernethy, who devised ${ }^{\text {66 }}$ practical definitions for neoplasms based upon their resemblance in gross arrangement and constitutional tendency to normal organ structures. Abernethy's classification, and other contemporary efforts along these lines, ${ }^{10}$ constitute the first steps towards the modern principles of tumour morphology:

His work on 'Tumours' contains much that is interesting in regard to the peculiar character of his mind, and his aptitude for simplification. He does not undertake a thorough investigation of the subject. His object seems to have been to place in an intelligible order; to chronicle and mark that which was really known; to pack together, as it were, that which was clear and positive, in a form convenient for consideration; to remove that disorder and obscurity which seem to hang about the threshold of all inquiries, and substitute so much of arrangement and perspicuity, as might invite, and perhaps facilitate further investigations. ${ }^{\circ 7}$

The Queries, as suggested above, undoubtedly stimulated explorations on cancer throughout the domain of British medicine, a notable example of which appears in the work of the Irish surgeon, Richard Carmichael. ${ }^{68}$

Thomas Denman weighed clinical findings for evidences of improvement in the treatment of cancer; in later years his conclusions were reported as Observations on the Cure of Cancer. ${ }^{20}$ There is no doubt that Denman not only encouraged similar activities within his circle of associates, but that he also urged his colleagues to undertake works of discovery on the unanswered issues raised by the Queries. Neither is it unreasonable to suppose that during the era of the Cancer Institution Denman tried his own hand at research, in a manner represented in the "diaries of John Knyveton'.69 An entry on 12 September 1803 offers the following comment on the subject:

Quite pleased to return from our annual holiday at Weymouth, agreeable as it is-but I am growing very interested in the subject of the Scirrhous Structure, or Cancer-and Mr. Clift, now proud Curator of the College of Surgeons, had promised whilst I was away to look out some good specimens of the Fungus Hematodes, ${ }^{*}$ the Scrofula, and the Scirrhous Structure, so that I might be able to study them by comparison. They are specific diseases which possibly have a common root? though their features diverge sharply as they progress to maturity. The structure of the Scrofulous Tubercle in most respects resembles that of a Scrofulous lymphatic gland, suppuration of a yellow or pale grey character arising without any signs of inflammation. The terms Scirrhous and Cancer, on the other hand, are used to express two stages of the same morbid affection, the first signifying the occult, and the second the ulcerated state of the disease. When a scirrous tumour is examined, the structure is hard, firm, rugged, consisting of fibrous septa, disposed in various directions, and a number of cells, or irregular cavities, containing a soft part. But the cause, primary seat, and manifestation of these Specific Diseases are both baffling and absorbing. One cannot solve their riddle, yet one cannot leave it alone. Why is it that Scirrhous, for example, in its primary form commonly attacks glands whose function has been interrupted or those which have never performed the offices intended for them? And is Doctor Jenner right in supposing that Hydatid Disease is but an occult manifestation of Scrofula? In his later years, John Hunter occasionally used a microscope. I think perhaps I will invest in one. If it does no more, it will assist my tired elderly eyes to detect the structure of the tumours more accurately. ${ }^{70}$

\section{In an entry dated 12 March 1804 we learn the outcome of this episode:}

My microscope is providing very useful-for reading small print in the newspaper. I am afraid the use of the instrument in medicine is extremely limited, to measuring the globules in the

*The Fungus hematodes was first described in 1803 by William Hey, cf. Practical Observations in Surgery, Illustrated with Cases, London, 1803, pp. 233-85. Contemporary bewilderment on the nature of this lesion is typically expressed in the sixth Query (Edin. med. surg. J., 1806, 2, 386), 'Mr. Hey of Leeds, in a late publication, has given an account of a new or hitherto imperfectly described disease, which he calls Fungus Hematodes, which, as it is incurable, we have no better way of classing than as a 'species of cancer.' 


\section{Victor A. Triolo}

blood and so forth. A pity-to the sour amusement of Mat[thew Baillie?], I wasted a good hour last monday with the glass over some slices cut from a mammary tumour, of which an elderly female died in the wards of St. George's."

As the year 1805 drew to a close, the cancer charity was brought to an abrupt end. Despite a modest achievement of its clinical aspirations, the establishment was not rewarded with the striking successes that attended the Fever Institution. The founders of the Cancer Institution seized upon the pretexts of distance and inconvenience to discharge themselves of further responsibilities to a foundering cause. Yet the hope for its renewal lingered in the coterie of medical men and laymen that appears to have survived the 'House' on Henry Street. The Cancer Society, nevertheless, deprived of its practical arm ceased to be an effective organ in the deployment of intellectual resources against a dreaded disease.

Cancer research institutes, in effect, autonomous organizations engaged in fundamental studies on causation and treatment, are scientific offsprings of the twentieth century: they post-date the origins of hospital departments devoted to similar purposes. ${ }^{72}$ Institute-centred research especially lends itself to multidisciplinary approaches, in which applications of the basic sciences are made with respect to the elucidation and repair of disease processes. In this respect there is little similarity between the Cancer Institution and the Imperial Cancer Research Fund, a remote successor, founded in 1902 upon the modern concept of institutionalized programmes. ${ }^{73}$ What, then, are we to conclude about the development in the preceding century?

One argument proceeds thus. The Cancer Institution lacked the appropriate underpinnings within the accepted structures of medicine at the turn of the nineteenth century. Let us once again consider that parallel previously made with respect to the Fever Institution. ${ }^{74}$ At its inception the House of Recovery, barely sustained by its original endowment, accommodated sixteen beds. By 1804 a total of three hundred and thirty patients had been admitted to its wards; in the years down to 1817 the number of annual admissions amounted to sixty-three patients. The subsidy derived from Parliament and monetary support received from private sources, such as the Poor Society, were used for the purchase and accoutrement of two wings annexed to the Smallpox Hospitals at Pancras Road '... a situation admirably calculated in all respects; with arcades and space for the convalescents to take air and exercise, and so separated and secluded from other habitations, as not to leave ground for the least alarm of infection to the most timid mind.75

Whereas the Fever Institution, in 1813, fulfilled its destiny as a hospital department, the Cancer Institution had a well established counterpart, the Cancer Ward founded at the Middlesex Hospital in June 1792. Late in 1791 John Howard (d. 1811), surgeon of Argyll Street, approached the Middlesex governors with a plan for the relief of indigents suffering from cancer. ${ }^{54,76}$ Such patients were to be admitted to a separate ward, to be maintained there 'until relieved by art or released by death', ${ }^{77}$ at the behest of an anonymous benefactor, who lodged $£ 3,000$ for this purpose. After his death, in 1796, the benefactor was identified as Samuel Whitbread, the famous brewer. The governors, in appreciation of this most seasonable gift, ${ }^{78}$ thereupon invited the younger Whitbread ${ }^{79}$ to participate as a trustee of the cancer fund. Howard subsequently (1797) became 'surgeon-extraordinary' to the Cancer Ward, which connection he retained until his death.

The architect of the Cancer Ward envisioned a broad design, ${ }^{80}$ inclusive of medical services comprising in- and out-patients departments, as well as accommodation for the conduct of research on the nature and cure of cancer. Contemporary accounts of early activities at the Middlesex cancer charity are disclosed in the published observations of Howard ${ }^{81}$ and in a contemporary treatise by the surgeon, Samuel Young. ${ }^{82}$

The Cancer Institution, which possessed neither the patronage of a great hospital, nor the exclusive loyalties of its resident staff, thus entered into an unequal 


\section{Institution for Investigating the Nature and Cure of Cancer}

rivalry with the Middlesex Hospital. Subtle undercurrents of this disquieting situation course through the Edinburgh Medical and Surgical Journal account, in which the Medical Committee speaks about never having 'entertained the idea of creating the jealousy, or of interfering with the interests of those who are engaged in institutions of a similar kind.' The closing phrase of the Highmore account, moreover, serves a reminder that the administration of cancer treatment and research rightfully belonged to the hospitals. And on this plane the question would remain for another century.

\section{ACKNOWLEDGEMENT}

The preparation of this work was greatly aided by the advice and interest of the following: Dr. Michael B. Shimkin, Temple University, and Dr. W. B. McDaniel, 2nd, the College of Physicians of Philadelphia. The technical assistance of Miss Shirley Purcell is gratefully acknowledged.

\section{REFERENCES}

1. Chaplin, ARnold, Medicine in England during the Reign of George III, The Fitzpatrick Lectures delivered at the Royal College of Physicians, 1917-18, London, 1919, p. 46.

2. BAILlIE, MATtHEW, The Morbid Anatomy of Some of the Most Important Parts of the Human Body, London, J. Johnson, 1795. Baillie's A Series of Engravings, Accompanied with Explanations, which are Intended to Illustrate the Morbid Anatomy of Some of the Most Important Parts of the Human Body . . ., was issued between 1799 and 1802 (2nd. ed., 1812).

3. WARDROP, JAMES, The Works of Matthew Baillie, M.D., to which is Prefixed an Account of his Life, Collected from Authentic Sources, 2 vols., London, T. N. Longman, 1825 , vol. 1 , p. xxix.

4. MunK, W., Roll of the Royal College of Physicians of London, 2nd ed., London, 1878, vol. 2, pp. 402-12.

5. Willan, R., On Cutaneous Diseases, vol. 1, London, J. Johnson, 1808. No other volume was published. From 1798 to 1808 the work appeared in parts as 'Description and treatment of cutaneous diseases', cf. LANE, J. E., 'Robert Willan', Arch. Dermat. Syph., 1926, 13, 758.

6. Bateman, T., 'Biographical Memoir of the late Dr. Willan', Edin. med. surg. J., 1812, 8, 502; also Munk, Roll, 2, 350-53.

7. Twelve medical societies were formed in England during the reign of George III; before 1760 only three existed. (Chaplin, op. cit., p. 23). For a detailed treatment of the question, see Clark, G., A History of the Royal College of Physicians of London, 2 vols., Oxford, Clarendon Press, 1964-66, vol. 2, pp. 603-4, et passim.

8. 'To a London whose surgeons and physicians knew next to nothing of anatomy came William Hunter, to introduce methods of anatomical instructions still hardly surpassed today. He made available, so far as was possible in conservative Britain, greatly increased numbers of cadavers for study'. OPPENHEIMER, JANE M., New Aspects of John and William Hunter, New York, H. Schuman, 1946, p. 120.

9. The eighteenth century witnessed the creation of the Westminster, St. George's, Guy's, the Middlesex, and the London hospitals, among others. This development greatly aided the growth of the medical professions, especially in London. ClaRK, op. cit., 2, p. 541 : also COPE, ZACHARY, The Royal College of Surgeons of England, A History, London, A. Blond, 1959, p. 4.

10. Bichat and his school mark the point of departure for the modern era of oncology. See ACKerkneCHT, E. H., 'Historical notes on cancer', Med. Hist., 1959, 2, 116; cf. Triolo, V. A., 'Bichats Krebstheorie in Wolff's "Lehre von der Krebskrankheit". Eine Berichtigung', Sudhoffs Arch. Ges. Med. Naturw., 1964, 48, 82-86.

11. Pott, Percival, Chirurgical Observations relative to the Cataract, the Polypus of the Nose, the Cancer of the Scrotum, the Different Kinds of Ruptures and the Mortification of the Toes and Feet, London, 1775, pp. 63-68. A reprint and discussion of this 


\section{Victor A. Triolo}

chapter ('Cancer scroti') appears in a recent review by M. PoTter (Percival Pott's Contribution to Cancer Research), National Cancer Institute Monograph, No. 10, 1962, pp. 1-13.

12. Dobson, Jessie, 'John Hunter's view of cancer', Ann. Roy. Coll. Surg. Eng., 1959, 25, 176-81. Hunter's theory of cancer is treated in detail by J. WoLFF, Die Lehre von der Krebskrankheit von den ältesten Zeiten bis zur Gegenwart, 4 vols, Jena, G. Fischer, 1907-28, vol. 1, pp. 79ff.

13. The Queries are typical of the Hunterian school, which considered the problem of cancer from the combined viewpoints of pathological anatomy, natural history and epidemiology. See HaYward, O. S., "The history of oncology. II. The Society for Investigating Cancer, London', Surgery, 1965, 58, 586-99.

14. 'Institution for Investigating the Nature and Cure of Cancer', Edin. med. surg. J., 1802, 2, 382-89. For a facsimile of this report, see StrmkIN, M. B., 'Thirteen questions: some historical outlines for cancer research', J. Nat. Cancer Inst., 1957, 19, 298-305.

15. Hayward, loc. cit., considers the Edinburgh Medical and Surgical Journal report the only surviving trace of the Cancer Society of 1802 , which he views as an organization of laymen and medical men. See also Hayward's 'History of oncology. 1. Early oncology and the literature of discovery', Surgery, 1965, 58, 468. Wolff (op. cit., 1, 83), who cites the same source, considers this development a prototype of modern cancer unions. An unsuccessful search for other evidences of the society, especially the brochure alluded to in the first Excerpt, was undertaken by C. D. Haagensen ('An exhibit of important books . . . illustrating the evolution of the knowledge of cancer'), Am. J. Cancer, 1933, 18, 42-126, p. 61.

16. The relevance of the Queries to modern currents of cancer research is shown by Shimkin, op. cit., 295-96, and Hayward, op. cit., 586.

17. BerNaRD, Thomas, 'Extract from an account of the Institution for Investigating the Nature and Cure of Cancer', Reports of the Society for Bettering the Condition and Increasing the Comforts of the Poor, 1802, 3, 355-63.

18. Although this appears to be one of the earliest medical charities devoted exclusively to the study and cure of cancer, institutions of a similar design were in existence at this time. For example, several close analogies obtain with respect to the Cancer Institution, the Institution for the Cure and Prevention of Contagious Fever, and the Cancer Ward of the Middlesex Hospital. These parallels will be developed elsewhere.

19. BERNARD, op. cit., pp. $360 \mathrm{ff}$.

20. Denman, Thomas, Observations on the Cure of Cancer, London, J. Johnson, 1810, pp. 87-90.

21. Highmore, A., Pietas Londinensis: The History, Design, and Present State of the Various Public Charities in and near London ..., London, Cradock \& Joy, 1814, pp. 95-97.

22. Ibid. p. 97. Rep. Soc. B.C. Poor, iii, 259, should read Rep. Soc. B.C. Poor, iii, 359.

23. Munk, Roll, 2, 333-35; also see 'Biographical sketch of Dr. Denman' in: Denman, T., An Introduction to the Practice of Midwifery, 7th ed., London, E. Cox, 1832, p. lv. This notice is divided into two parts: 'A memoir of my own life' (lv-lxxiii), written by Denman in 1779, and a continuation (lxxiii-lxxix) to Denman's death, appended by Matthew Baillie.

24. Denman's career is suggested in Ernest Gray's reconstruction of an eighteenth-century surgeon represented in the Knyveton trilogy: The Diary of a Surgeon in the Year 1751-1752, ed. and transcribed by Ernest Gray, New York, Appleton-Century Co., 1937; Surgeon's Mate: the Diary of John Knyveton in the British Fleet during the Seven Years War, 1756-1763, ed. and transcribed by Ernest Gray, London, R. Hale, 1942; Man Midwife: the Further Experiences of John Knyveton, M.D., late Surgeon in the British Fleet, during the Years 1763-1809, London, R. Hale, 1946. See note 69 for an additional comment on this subject.

25. Denman's election, in 1770, to the office of 'man-midwife' at the Middlesex Hospital 


\section{Institution for Investigating the Nature and Cure of Cancer}

suggests the possibility of his association with the Cancer Ward established at that Hospital in 1792. Denman, An Introduction to the Practice of Midwifery, 7th ed., 1832, p. 1xx.

26. Denman's concern with cancer is characterized by his son-in-law, Matthew Baillie (ibid., p. lxxviii): 'He [Denman] was very much interested in this subject [cancer], knowing the disease to be so afflicting to human nature, and because he thought that of late years some improvement had been made in its pathology, that its treatment also, both with respect to external and internal remedies, had been improved.'

27. See biographical review by Sir D'Arcy Power in Dictionary of National Biography, 1908-9, 15, 618-19.

28. Ibid., p. 618.

29. Pearson, John, Practical Observations on Cancerous Complaints: with an Account of Some Diseases which have been confounded with Cancer ..., , London, J. Johnson, 1793.

30. The Edinburgh Medical and Surgical Journal report praises Pearson's work on cancer. However, Hayward (p. 586) minimizes his effort with the comment, 'He [Pearson] was no original thinker, nor was his treatise of 1793 so complete that the activities of the society were rendered unnecessary by 1802 -as the learned editors of the Edinburgh Journal seemed to think'. There is nothing in the text of the Edinburgh Journal that would justify this conclusion. The acknowledgement of Pearson's treatise is intended as a tribute to his precedence, among his peers, as a student of cancer.

31. BAKER, JAmes, The Life of Sir Thomas Bernard, Baronet, London, J. Murray, 1819; also see biographical review by T. F. Henderson in Dictionary of National Biography, 2, 387-89.

32. BAKER, op. cit., pp. 69-70. Note that the Bernard account alludes to an endowment provided the Cancer Institution by the Patrons of the Infant Asylum.

33. Stephen Aisley, Esq., Kensington, Treasurer of the Cancer Society, appears on the membership lists of the Poor Society as early as 1797-98. See 'Account of the Society, its object, subject of inquiry, regulations, etc.', Reports of the Society for Bettering the Condition and Increasing the Comforts of the Poor, 1798, 1, 262-86, p. 274.

34. The design of the cancer charity suggests Bernard's handiwork, especially the methods employed for the solicitation of funds, which resemble the procedures followed in other enterprises of the Poor Society. A fee of thirty guineas was required for enrolment as a life-governor of the Cancer Institution; the cancer warders at the Middlesex Hospital levied a sum of fifty pounds for each life-governership. Cf. Highmore, op. cit., p. 226.

35. MunK, Roll, 2, 227-28.

36. Ibid., 2, 213-18.

37. Ibid., 2, 457-60.

38. Ibid, 2, 317-18.

39. COPE, op. cit., pp. $323,339,341$.

40. Ibid., pp. 310, 339, 341; see also Dictionary of National Biography, 2, 685.

41. CoPe, op. cit., pp. 321, 339, 341; see also Dictionary of National Biography, 9, 1121-22.

42. Home, Sir Everard, Observations on Cancer with Connected Histories of the Diseases, London, 1805; also Home, E., A Short Tract on the Formation of Tumours, and the Peculiarities that are met with in the Structure of those that have become Cancerous, with their Mode of Treatment, London, T. N. Longman, 1830.

43. Macilwain, George, Memoirs of John Abernethy, F.R.S., with a View of his Lectures, Writings, and Character, 2nd ed., 2 vols., London, Hurst \& Blackett, 1854.

44. COPE, Op. cit., p. 307.

45. Abernethy, J., Surgical Observations containing a Classification of Tumours . . . , London, T. N. Longman \& O. Rees, 1804.

46. Cope, op. cit., pp. 313-14, 339, 341; Dictionary of National Biography, 4, 544-45.

47. Chaplin, op. cit., p. 138. 


\section{Victor A. Triolo}

48. The nineteenth-century surgical authority on cancer, Sir Astley Cooper, was a student of Cline and succeeded him at St. Thomas's. Dictionary of National Biography, 4, 545.

49. Here one is reminded of Samuel Sharp (1700?-1778), student of William Cheselden, who became a famous operator at Guy's Hospital. Sharp instituted the course of anatomical lectures that was ultimately absorbed within Hunter's Great Windmill Street School. He was a prolific writer and an outstanding surgeon in the eighteenthcentury style. See Dictionary of National Biography, 17, 1352-3.

50. The Henry Street of this era no longer exists. In 1803 the vicinity of Tottenham Court Road from Oxford Street to the present Euston Road, then part of the 'New Road from Paddington to Islington', was well-settled and in much the same form that it retains today. Tottenham Court Road continued a brief distance above this point approximating the route that now marks Hampstead Road. This, then a sparsely populated area, was interspersed with country lanes, one of which presumably was Henry Street. Within a relatively remote district the Cancer Institution appears to have escaped the notice of contemporary exhibitors of the London scene. Feltham, John, The Picture of London for 1803, London, R. Phillips, 1803, 130-68, 366-7 and map facing p. 384.

51. BeRnARD, SIR ThOMAs, 'Extract from an account of the institution to prevent the progress of the contagious fever in the metropolis', Reports of the Society for Bettering the Condition and Increasing the Comforts of the Poor, 1802, 3, 271-88; also Baker, Life of Bernard, pp. 70ff., and Lane, op. cit., pp. $12 \mathrm{ff}$.

52. WILlan, Reports of the Diseases in London . . . , London, 1801, pp. 259-60.

53. Bateman, op. cit., p. 505.

54. Until the second half of the nineteenth century cancer was generally considered to be a contagious disease, resembling leprosy, and most hospitals barred the admission of cancer patients. (ACKERKNECHT, E. H., History and Geography of the Most Important Diseases, New York, Hafner, 1965, 67.) The singularly hard lot of 'cancerous paupers' was brought to the attention of the Governors of the Middlesex Hospital, in 1791, by the London surgeon John Howard. Howard's plan for a cancer department within the hospital was adopted subsequently. We will return to this question elsewhere in the text. See HowarD, J., The Plan adopted by the Governors of the Middlesex Hospital for the Relief of Persons afflicted with Cancer: etc., London, 1792; also CouPLAND, SIDNEY, 'The Cancer Charity of the Middlesex Hospital, 1792-1902', in: Reports from the Cancer Research Laboratories of the Middlesex Hospital, London, 1902, 1, 2-3.

55. The fifth Query examines this proposition: 'Does it [infectivity from cancer] imply a possibility of cancer being conveyed from one person to another by the breath, as in the hooping-cough, and, as some have suspected, in consumption? or by effluvia exhaled from a body afflicted with this disease, as in infectious fevers? or, by the breath passing over an ulcerated surface, as in cancer of the mouth or lip?' Edin. med. surg. J., 1806, $2,385$.

56. MunK, Roll, 3, 41-43.

57. Peacock, George, Life of Thomas Young, M.D., F.R.S., London, J. Murray, 1855, pp. 32-39, 47, 131-37, 211-12; also MuNK, Roll, 3, 80-88.

58. GURNEY, Hudson, Memoir of the Life of Thomas Young, M.D.,F.R.S., with a Catalogue of his Works and Essays, London, J \& A. Arch, 1831, p. 23. See also PeAcock, op. cit., pp. 211-20. Cf. Weld, Charles Richard, A History of the Royal Society with Memoirs of the Presidents, 2 vols., London, J. W. Parker, 1848, 2, 236.

59. Pearson was made a Fellow of the Royal Society in March 1803. Dictionary of National Biography, 15, 618.

60. The unsavoury character of this art was thus noised abroad in 1803: 'Although there is also a Society of Apothecaries, with exclusive privileges and immunities, any person, however ignorant, may vend medicine to the public, but persons who desire to have unadulterated drugs, may place the most reliance on what are sold at Apothecarieshall in Blackfriars. As a fact worth attention, but much to be lamented, we close 


\section{Institution for Investigating the Nature and Cure of Cancer}

this account with the following notice respecting the state of empiricism; namely, that the nett amount of the stamp-duties on quack-medicines sold in England during the last year, amounted to more than $14,000 \mathrm{l}$. sterling, exclusively of a very large sum arising from the duties on empiric advertisements!' Feltham, op. cit., 169-70. The status of the apothecaries during the early nineteenth century is discussed by Clark, op. cit., 2, 606 et passim; See also Holloway, S. W. F., 'The Apothecaries' Act, 1815, a reinterpretation', Med. Hist., 1966, 10, 107-29, 221-36, p. 108.

61. WARDROP, op. cit., p. xxxiii.

62. For example, Fasciculus 9 (plate 1, 185) of Baillie's Engravings (2nd ed., 1812) shows an excellent example of cancer of the uterus.

63. Home, Observations on Cancer, p. iii. Home frequently cites the clinical experiences with respect to cancer of Sir William Blizard and Henry Cline.

64. Medical men of this era often refused treatment to incurables on the grounds of sound practice (Cf. ACKERKNECHT, History and Geography of Diseases, p. 164). HOME (Observations on cancer, p. vi) assailed this concept of pessimism, 'Cancer is a disease which must engage the attention of every practitioner in surgery, in a greater or less degree, for even those who have no particular turn for investigation, must be led, by feelings of humanity, to employ their minds upon the consideration of a complaint, which so frequently baffles all their skill, and destroys such numbers of both sexes, but particularly females. It is a truth, which cannot be denied, that in so extensive a field as surgery, those diseases for which we have no cure, are commonly neglected by the professors of the art: they are left in despair, for others, which, being more manageable, are attended to with infinitely more satisfaction.'

65. HOME, Observations on Cancer, p. vii.

66. ABERNETHY, Surgical Observations, pp. 1-107, which section is titled, 'An attempt to form a classification of tumours according to their anatomical structure'. Abernethy (p. 2) states a motive for his undertaking, 'The Society for the Investigation of the nature of cancer have enquired about the anatomical structure of that disease, and about other disorders which have a resemblance to it. In the present paper I have attempted to reply to such investigations as far as my knowledge enables me.'

67. MaCILWAIN, op. cit., 1, 209. Abernethy's contribution indeed invites comparison with studies carried out by Laënnec and other workers on the Continent. Cf. TRIOLO, V. A., 'Nineteenth century foundations of cancer research. Advances in tumor pathology, nomenclature, and theories of oncogenesis', Cancer Res., 1965, 25, 75-106, pp. 78ff.

68. CaRmichael, Richard, An Essay on the Effects of Carbonate, and Other Preparations of Iron, upon Cancer . . . , 2nd ed., Dublin, G. A. Procter, 1809, 467-89. These pages encompass 'An attempt to answer the queries of the Medical Committee of the Society for Investigating the Nature and Cure of Cancer. These additions are not found in the first (1806) edition.

69. The Knyveton chronicles have given rise to an unusual controversy. The publication of Man Midwife occasioned a series of letters to the Times Literary Supplement, one of which by J. B. Whitmore, published 7 September 1946, established that the subject of Gray's narrative, John Knyveton, bore a striking resemblance to the biographic character of Denman. A riposte by Gray, published in The Times on 28 September 1946, stated that Man Midwife was an expansion of an original document written by an eminent eighteenth-century physician, whose 'real name is concealed under the alias of John Knyveton because the physician's old hospital asked that his real name should not be disclosed, and also because certain of his descendants are alive today'. Gray's representation however, has not withstood the scrutiny of critics, who find it replete with anachronism and discrepancy. It is remarkable, nevertheless, that Gray could have produced such a sketch without recourse to some primary evidence, such as original diaries and private journals, although the nature of these sources has never been revealed.

70. Gray, Man Midwife, pp. 202-3. The sense of this argument applies to the sixth Query, 


\section{Victor A. Triolo}

'Is there any well-marked relation between cancer and other diseases? If there be, what are those diseases to which it bears the nearest resemblance, in its origin, progress, and termination?' The comments appended to this Query in the Edinburgh Medical and Surgical Journal (1806, 2, 385-6) outline considerations similar to those advanced in the Knyveton entry quoted on the text.

71. Gray, Man Midwife, 203. Dissatisfaction with the use of the microscope was common to investigators of this period. Thus Bichat, in 1800, dismissed microscopy for its entirely inconsistent results. Cf. BRADBURY, SAVILE, The Evolution of the Microscope, Oxford and New York, Pergamon Press, 1967, p. 184.

72. DUKes, CUTHBERT E., 'The origins and early history of the Imperial Cancer Research Fund', Ann. Roy. Coll. Surg. Eng., 1965, 36, 325. Reviews of the modern foundations of hospital-centred cancer research are given by BRUNNING, D. A., and DuKEs, C. E., 'The origin and early history of the Institute for Cancer Research of the Royal Cancer Hospital', Proc. R. Soc. Med., 1965, 58, 33-36; and Handley, W. S. (ed.), Cancer Research at the Middlesex Hospital, 1900-1924 . . . , London, Middlesex Hospital Press, 1924, pp. 1-6.

73. BASHFORD, E. F., Draft scheme for enquiring into the nature, cause, prevention, and treatment of cancer: Appendix (II) to the Third Report of the Imperial Cancer Research Fund, London, 1908. A facsimile of this report has been issued by Shimkin, Thirteen Questions, 307-14. This Fund was established under the joint auspices of the Royal College of Physicians of London and the Royal College of Surgeons of England. Cf. Fifty years of cancer research, 1902-1952: Supplement to the FortyNinth Annual Report of the Imperial Cancer Research Fund, London, 1952.

74. BAKER, Life of Bernard, 72-73.

75. Ibid., p. 72.

76. Wilson, Sir William James Erasmus, History of the Middlesex Hospital during the First Century of its Existence, Compiled from the Hospital Records, London, 1845, pp. 44, 128-45; also HighMORE, op. cit., pp. 225-27, and CouplaND, op. cit., pp. 1-11.

77. Coupland, op. cit., p. 10.

78. It has been suggested that heavy financial losses of the Middlesex Hospital during the early years of the Anglo-French conflict were offset by the Whitbread bequest. See SAUnders, H. ST. G., The Middlesex Hospital, 1745-1949, London, M. Parrish, 1949, pp. 18-19.

79. Samuel Whitbread (1758-1815), M.P. from Bedford and member of the Whig faction, supported poor law legislation and other measures intended for the relief of the dispossessed and disenfranchized. Whitbread took an active interest in the affairs of the Middlesex Hospital and shortly before his death, on the eve of Waterloo, he arranged the appointment of Charles (later Sir Charles) Bell as surgeon to the Middlesex. See Dictionary of National Biography, 21, 24-28.

80. HowARD, JoHn, The Plan adopted by the Governors of the Middlesex Hospital for the Relief of Persons Afflicted with Cancer . . . , London, 1792, pp. 1-11.

81. Howard, John, Practical Observations on Cancer, London, J. Hatchard, 1811, p. iv.

82. The London surgeon, Samuel Young, author of the theory of 'natural separation' for the cure of cancer, cites some of the cancer case work about 1795, at which time he was house-surgeon at the Middlesex. (Young, SAMUEL, An Inquiry into the Nature and Action of Cancer: with a View to the Establishment of a Regular Mode of curing that Disease by Natural Separation, London, R. Phillips, 1805, pp. 6-10, 66). Young seems to have fallen into disfavour. His name next appears in 1815, affixed to another treatise in which he proposed a new cancer treatment, the 'method of compression'. This work produced a testimonial letter from the younger Whitbread, who recommended Young's method for trial at the Middlesex Hospital. See Youna, S., Minutes of Cases of Cancer and Cancerous Tendency, successfully treated by Mr. Samuel Young, Surgeon: with a Prefatory Letter addressed to the Governors of the Middlesex Hospital by Samuel Whitbread, Esq., M.P., London, E. Cox and J. Ridgeway, 1815, pp. iii-x. 